\title{
Novel Combined Preparation and Investigation of Bergenin Loaded Albumin Nanoparticles for the Treatment and Care of Acute Lung Injury: In Vitro and In Vivo Evaluations
}

\section{Lingqiao Yan}

First People's Hospital of Wenling

Hui Chen

First People's Hospital of Wenling

Mindan Xie ( $\sim$ mindan.xie@yahoo.com )

First People's Hospital of Wenling https://orcid.org/0000-0002-4041-6997

\section{Research Article}

Keywords: Bergenin, BSA, ALI, LPS, Drug delivery

Posted Date: May 26th, 2021

DOl: https://doi.org/10.21203/rs.3.rs-532100/v1

License: (c) (1) This work is licensed under a Creative Commons Attribution 4.0 International License.

Read Full License 


\section{Abstract}

A new method for targeting lung infections is of great interest using biodegradable nanoparticles. In this study, bergenin loaded BSA NPs were developed against lung injury. Briefly, BG@BSA NPS were synthesized and characterized. HPLC recorded the major peak of bergenin. UV-vis spectra had an absorbance at $376 \mathrm{~nm}$. XRD revealed the presence of crystalline particles. FTIR confirmed the occurrence of functionalized molecules in the synthesized NPS. The particles were highly stable with a net negative charge of -24.2. The morphology of NPS were determined by SEM and TEM. The mean particle size was $124.26 \mathrm{~nm}$. The production of NO by NR8383 cells was decreased by BG@BSA NPs. Also, in mice, lipopolysaccharide mediated acute lung inflammation was induced. BG@BSA NPs reduced macrophages and neutrophils in BALF and remarkably enhanced wet-to-dry weight (W/D) ratios and myeloperoxidase (MPO) activity. Further, BG@BSA NPs inhibited the production of inflammatory cells as well as tumour necrosis factor. The histopathological studies revealed that the damage and neutrophil infiltration was greatly inhibited by BG@BSA NPs. This indicates that BG@BSA NPs may be used to treat lung infections Therefore, this study has given new insight into producing an active drug for the treatment of lung associated diseases in the future.

\section{Highlights}

- Synthesized bergenin (BG) loaded albumin (BSA) BG@BSA NPs and characterized.

- Effects of BG@BSANPs on the cell viability of NR8383 was tested.

- Histopathology of lung tissues was examined.

- MDA and SOD activity treated with BG@BSA NPs was increased.

\section{Introduction}

Acute lung injury (ALI) is a serious health problem responsible for increased morbidity and mortality [1]. There is a need to develop new treatment plans for ALI. However, a great challenge occurs in evolving drugs to treat ALI particularly to block the cytokines and chemokines due to the complex pathogenesis of the disease [4]. Therefore, there is a growing need for targeted therapies to specifically block the signaling pathways and to lung disease [5]. Various targets that regulate signaling pathways that intensify inflammation are identified as better therapeutics for ALI. However, a great challenge arises in the delivery of targeted drugs to the specific region of lungs and cure the problems [6].

Recently, nanomedicine has gained significant interest in effective delivery of drugs to the lung $[7,8]$. Nano-drug delivery models can increase bioavailability, and enhance drug release. These approaches could increase the distribution of therapeutic agents to target organs, improved efficacy and limit drug toxicity $[9,10]$. Among the different drug delivery methods used for lungs, the use of immunomodulators and protein nanoparticles are highly advantageous [11]. These procedures are effective to treat adult respiratory diseases [6]. Also, a number of different approaches have been practiced to modify the 
characteristics of the nanoparticle to target the cells and organs. This method of drug delivery is highly effective to fight inflammatory diseases such as ALI.

Recent drug delivery systems possess the short lung-site deposition effectiveness. This is due to the deposition of drugs in the oral cavity. Therefore, the developing of targeted drug delivery has been necessitated. With the development of targeted drug delivery, it is possible to efficiently administer the drugs to the target area. The delivery of respiratory drugs can be accomplished by controlling the drug aerosols releasing activity. Aerosol preparations that can target lung is needed. For a long time, nano preparations for delivery the drugs to the specific site of lungs have been practiced. For inhalation therapies, controlled drug delivery is promising $[12,13]$. The greater surface area of the lung makes it ideal for a variety of therapeutics [11]. Among the different drug delivery systems, nanoparticles have prolonged drug release and cell-specific drug release $[14,15]$. Nanoparticles composed of biodegradable compounds have a potential to be transferred into aerosol, biocompatibility, target-specific, release manner, and degradation [16].

In this study, we have combined albumin and bergenin, which is a trihydroxy benzoic acid glycoside. It has an 0-demethylated derivative called norbergenin. These compounds popularly known as Paashaanbhed are commonly used in Ayurveda. It has a potent immunomodulatory effect. This innovative approach consists of bergenin loaded albumin nanoparticles (BG@BSANPs) for the treatment of lung diseases and management of nursing care.

\section{Materials And Methods}

\subsection{Chemical and reagents}

HPLC solvents, bovine serum albumin (BSA), glutaraldehyde and methanol were purchased from Sigma Aldrich. All other chemical and reagents used in this study was high analytical grade.

\subsection{Preparation of BG@BSANPs}

Albumin nanoparticles were prepared using bovine serum albumin [17]. Briefly, 50mg of BSA was mixed to bergenin (BG) $\left(0.5 \mathrm{mg} \mathrm{mL}^{-1}\right)$ in ethanol and stirred continuously. Then, glutaraldehyde (8\%) was added as cross-linking agent and stirred for $24 \mathrm{~h}$. The resulting product was purified by repeated centrifugation $(12,000 \mathrm{~g})$ and the collected NPs was redispersed in distilled water. The synthesized NPs were confirmed by bio-physical characterization.

\subsection{Characterization of BG@BSANPs}

The absorbance was measured by a UV-Vis spectrophotometer (Ultrospec 2000, Scinteck, UK) at a wavelength ranging from 400 to $800 \mathrm{~nm}$. XRD was analyzed using PAN analytical X'PERT PRO model. The change in transmittance was recorded using FT-IR spectrophotometry in the range of $4000-400 \mathrm{~cm}^{-}$

1. The topography of particles was studied through SEM (EM 3200, KYKY, Chine) and transmission electron microscopy (TEM; H7500, Japan) at 120 kV, respectively. Thermal gravimetric 
analysis/differential thermal analysis (TGA/DTA) was used to examine the reaction type and weight loss of synthesized NPs. The spectrum of TGA/DTA has been recorded up to $1000^{\circ} \mathrm{C}$ in an air atmosphere at the heating the rate $20.0^{\circ} \mathrm{C} / \mathrm{min}$. The surface morphologies of the synthesized BG@BSANPs were observed through AFM (AFM, Agilent 5500).

\subsection{X-ray photoelectron spectroscopy}

XPS was performed on ESCA 3000 Spectrometer. XPS was used to detect the photoelectron.

\subsection{Drug loading efficiency}

Briefly, BG@BSA NPs were centrifuged (10000 rpm) for 15 min and the collected pellet was resuspend in PBS and measured the absorbance rate at $272 \mathrm{~nm}$. The percentage of BG loading efficiency was calculated using the following formula:

$\%$ BG loading $=($ Amount of BG loaded/Total amount of BG used $) \times 100$

\subsection{High-performance liquid chromatography (HPLC) analysis}

HPLC analysis was used to determine the presence of actual compounds present in NPs. Briefly, the sample was kept into the HPLC system $(250 \mathrm{~mm} \times 4.6 \mathrm{~mm}, 5 \mu \mathrm{m})$ and analyzed at a constant flow rate $(0.6 \mathrm{~mL} \mathrm{~min}-1)$. The column was maintained at $30^{\circ} \mathrm{C}$, and the applied wavelength was $254 \mathrm{~nm}$.

\subsection{Cell culture}

The NR8383 cell line (ATCC) was cultured in Ham F-12 medium (Invitrogen) with a supplementation of $15 \% \mathrm{FCS}$ and $60 \mathrm{lg} / \mathrm{ml}$ ampicillin under $5 \% \mathrm{CO}_{2}$ atmosphere. Then, the cells were treated with BG@BSA NPs. In this study, the cell viability was examined by trypan blue exclusion method.

\subsubsection{CCK-8 assay}

The cytotoxicity of the NR8383 cell line was evaluated using CCK-8 dye. CCK-8 is a non-radioactive dye used for the determination of cell surveillance under varying concentrations of NP. The principle of this assay to determine the dehydrogenases activity in the live cells as evidenced by the conversion of a tetrazolium salt into water-soluble formazan. Briefly, the cells were cultured along with CCK-8 dye in 96 well plate at $37^{\circ} \mathrm{C}$ for $1 \mathrm{~h}$ and read the absorbance at $450 \mathrm{~nm}$. The percentage of cell viability was calculated using the following formula

Cell viability $(\%)=\frac{(\text { OD450 treatment }- \text { OD } 650 \text { treatment })}{(\text { OD450 control }- \text { OD } 650 \text { control })} \times 100$ 


\subsection{Experimental Animal}

An acute lung injury was induced in mice by intratracheal injection of LPS $\left(2 \mathrm{mg} \mathrm{kg}^{-} 1\right)$. Totally, the mice were separated into six groups as follow as: one group of mice was injected with saline (control blank). One group of mice was orally administered with LPS daily along with saline (model control). A positive control (dexamethasone) was used. The mice were sacrificed for further study.

\subsubsection{Collection of lung lavage fluid and cell counting}

The mice were sacrificed to remove the right lung and was lavage using phosphate-buffered saline (PBS) thrice. Then, the BALF was centrifuged to collect pellets. The counting of cells was done by hemocytometer.

\subsubsection{Quantity analysis of wet-to-dry ratio}

The wet weight was measured using the left lung. The stable dry weight was measured by drying the tissue at $60^{\circ} \mathrm{C}$. The pulmonary edema was determined by the wet weight-dry weight ratio (W/D) of the lungs.

\subsubsection{Determination of MPO and inflammatory cytokine}

MPO activity is a valuable tool for detecting inflammatory neutrophil. Briefly, lung tissues were homogenized and centrifuged $(4500 \times \mathrm{g})$ for $10 \mathrm{~min}$. The supernatant was read at $460 \mathrm{~nm}$. This assay was studied at triplicates. Further, the inflammatory cytokine such as TNF-a, IL-1 $\beta$, and IL-6 in BALF were examined using commercial ELISA kits according to the manufacturer's instructions.

\subsubsection{Determination of antioxidant and lipid peroxidation activity}

The potential antioxidant and LPO activities were investigated using commercially available kits. The collected tissues were cleaned with PBS ( $\mathrm{pH}$ 7.4) and homogenate using glass mortar and pestle. Then the sample solution was centrifuged and collected supernatant was taken for the analysis.

\subsubsection{Histopathological analysis}

Lung specimens were excised, fixed in 10\% neutral buffered formalin for $24 \mathrm{~h}$, embedded in paraffin and sectioned at $4 \mathrm{~mm}$ thickness by rotary microtome. The sections were stained with hematoxylin and eosin (H\&E) stain for histopathological analysis. The pulmonary histopathological changes were examined using bright field microscopy at a magnification of 10 and 40x (Nikon ECLIPSE 90i microscope).

\subsection{Statistics}

Data were subjected to Analysis of Variance followed by Turkey's test. The results were given as mean \pm SD of three replicates.

\section{Results And Discussion}




\subsection{HPLC chromatogram of BG@BSANPs}

The principal compounds in BG@BSANPs were identified using HPLC by comparing their characteristics absorbance peak with those of standards. The both chromatograms of total ion current (TIC) and the corresponding HPLC (258 nm) were displayed in Fig. 1.

\subsection{Preparation and characterization of BG@BSANPs}

The desolvation method was followed for BG@BSA NPs production. Here, ethanol and glutaraldehyde were used as desolvating and cross-linking agent respectively [22]. As presented in schematic Fig. 2, this method validates the production of homogeneous distribution of least aggregated particles. Also, the particle remains stable both in water and culture medium. Glutaraldehyde is a water-soluble reagent and has the ability to form stable covalent bonds. It reacts with protein and forms Schiff bases between the amino groups and two carbonyl ends of glutaraldehyde. Thus, the BSA amino moieties are key in the formation of nanoparticles. The absorption maximum of BG@BSA NPs was assessed from 300 to 600 $\mathrm{nm}$ (Fig. 3a). Albumin shows a characteristic absorption peak at $270 \mathrm{~nm}$. However, bergenin recorded absorbance peak at 290nm. Interestingly, the bergenin encapsulated albumin NPs (BG@BSA NPs) showed a characteristic peak at $376 \mathrm{~nm}$. This change in spectra could be due to cross-linking of amino acids and the formation of protein-drug complex. The niclosamide drug encapsulated albumin NPs had shown a peak at $346 \mathrm{~nm}[18]$.

FTIR spectrum of BSA showed functional peaks at 1510.21, 1623.05, 3100, and $3356.28 \mathrm{~cm}^{-1}$ assigned to the $\mathrm{N}-\mathrm{H}$ and $\mathrm{C}-\mathrm{N}$ vibrations, stretching vibration of $-\mathrm{NH}, \mathrm{C}=\mathrm{O}$ stretching of the peptides and stretching vibrate of $-\mathrm{OH}$ respectively (Fig. 3b). Bergenin alone had a major peak at 1084.04 to 1176.10 , 1229.35 to 1247.90 and 1480.17 to 1501.05 indicating the involvement of the $\mathrm{C}-\mathrm{OH}, \mathrm{C}=\mathrm{O}, \mathrm{NO}_{2}$ groups of bergenin in the formation of a complex. Furthermore, the interaction between the nanoparticles have led to wide spectrum. A typical reduction in the stretching was observed in BG-BSA NPs (Fig. 3b). The peak of BSA shifted from 1623.05 to $3356.28 \mathrm{~cm}^{-1}$ may be attributed to the cross-linking of amino groups of proteins and the interaction of bergenin. It was demonstrated that electrostatic interactions help in the binding process of protein with a drug. Likewise, niclosamide interacts with the tryptophan residues (Trp 212) of BSA $[19,20]$.

The XRD pattern of bergenin and BG@BSA NPs is shown in Fig. 4(a). The synthesized NPs showed Bragg's reflection peaks at 38.4, 42.5, 63.2 and 76.4 in the $2 \mathrm{~h}$ range between 30 and 80 which can be indexed to the (220), (311), (400), (422) and (511) planes respectively. The diffraction peaks match with the standard JCPDS No: 04-0784. The thermogravimetric (TG) analysis of bergnin, BSA and BG@BSA NPs were performed (Fig. $4 \mathrm{~b}$ ). The degradation rate of NPs was slower indicating their improved stability compared to BSA and bergenin. At $300-600^{\circ} \mathrm{C}$, a remarkable difference in weight loss was noticed. On the other hand, only $10 \%$ was remaining for bergenin alone which confirmed the slower degradation potential of BG-BSA NPs when compared to bergenin alone. A faster degradation of BG-BSA NPs was observed compared to BSA at $>500^{\circ} \mathrm{C}$. This is because of the crystalline nature of NPs. The differential 
thermal analysis (DTA) of the bare bergenin showed an endothermic peak at $235^{\circ} \mathrm{C}$. However, BG@BSA NPs had greater stability compared to bergenin and albumin. This substantiates the amorphous nature of NPs as evident from Fig. 4(c). The increased amorphous nature of the therapeutic system contributes to the drug delivery efficiency of NPs [21].

The surface morphology of the BG@BSA NPs was determined by SEM and TEM analysis. BG@BSA NPS had a spherical shape with uniform size distribution as shown in Fig. 5(a). However, the TEM image reflected the hexagonal shaped particle as shown in Fig. 5(b). The size of BG@BSA NPs was measured by AFM (Fig. 5c). The average grain size was $124.26 \mathrm{~nm}$. The nanoparticles size was most important factor in drug delivery system. The particles less than $400 \mathrm{~nm}$ have increased permeability and retention (EPR) effect [22]. The element composition of BG@BSA NPs were measured using XPS analysis. The ratio of carbon was greater than that of oxygen, nitrogen, phosphorus and sulfur (Fig. 5d). The ratio of $\mathrm{C} / \mathrm{N}$ was much lower than that of HNP, in CS-NP [23]. BG@BSA NPs exhibited good stability which was confirmed by zeta potential analysis. Figure 6a showed the zeta potential value of BG@BSA NPs, it was found to be $-24.2 \mathrm{mV}$ while comparing to the values of BSA $(-18.9 \mathrm{mV})$. This result confirmed that BG@BSA NPs are highly stable. The electrostatic repulsive force of the negatively charged surface of NPs attributed to the higher stability of the colloidal solution [24]. The particle size analysis of BG@BSA NPs was shown in Fig. 6b. The mean size was found to be $124.26 \mathrm{~nm}$. However, the BSA NPs and bergenin were found to be $288.24 \mathrm{~nm}$ and $267.02 \mathrm{~nm}$ respectively in size. The size of NPs plays a key role in drug delivery, as the nanoparticles up to $400 \mathrm{~nm}$ get can have "enhanced permeability and retention (EPR)" effect [22].

\subsection{Drug loading efficiency and release profile}

The encapsulation efficiency of BG@BSA NPs was $90.15 \%$ (Fig. 7a). Previously, it was reported that BSA provides the encapsulation efficiency of 92.36\% [18]. The in vitro drug release profiles of BG@BSA NPs was studied at regular time intervals (Fig. 7b). Drug release is the diffusion and degradation of drug molecules into the external environment. The drug release was $36.25 \%$. The initial burst release is due to the surface bound bergenin, while the controlled release is due to the encapsulated bergenin. Our results are in close proximity with earlier reports on niclosamide based NPs [18].

\subsection{Effect of BG@BSA NPs on cell viability and NO production}

Briefly, NR8383 cells were treated with BG@BSA NPs (1-100 $\left.\mathrm{mg} \mathrm{mL}^{-1}\right)$ for $24 \mathrm{~h}$ and $48 \mathrm{~h}$ and the cell viability were determined following CCK8 assay (Fig. 8a). The viability of cells before LPS stimulation and measured nitric oxide (NO production). Following LPS stimulation, NR8383 cells had a greater level of NO production compared to the control cells (Fig. 8b). BG@BSA NPs slightly suppressed the NO releasing activity at a minimum concentration, but the inhibitory effect was strongly enhanced at 10 and $25 \mathrm{mg} \mathrm{mL}^{-1}$. Cells treated with BG@BSA NPs at 10 and $25 \mathrm{mg} \mathrm{mL}^{-1}$ showed $44 \%$ and $62 \%$ decrease in NO production respectively (Fig. 8c). NR8383 macrophages cells treated with BM60 had reduced NO production [25]. 


\subsection{Total cell count and lung wet to dry ratio}

Neutrophils are involved in the innate immune system in the lung. These cells can be found at the injury site and release numerous cytotoxic products [26]. In LPS induced group, the neutrophils modulated the expressions of TNF-a, IL-1b, and IL- 6 and finally cause the pulmonary injury [27]. The neutrophil count in this study was increased in the lung following LPS exposure. The effect of BG@BSA NPs on the inflammatory cells in BALF was shown in Fig. 9a. The animal administrated with LPS alone showed a significantly increased level of total cells count and neutrophils. Interestingly, the induced group of animals treated with BG@BSA NPs showed a decreased level of total cells count and neutrophils. This finding revealed that BG@BSA NPs had significantly reduced the neutrophils level in the lungs.

Lung wet-to-dry ratio was used to evaluate the pulmonary edema. It is a typical symptom of inflammation [28]. In this study, the lung wet/dry ratio was increased in LPS treatment (Fig. 9b). However, the lung wet/dry ratios were greatly decreased in animal treated with BG@BSA NPs, thus confirming the protective effect of BG@BSA NPs. BM60 decreased the lung wet-to-dry ratio, which suggested the protective effect on LPS-induced ALI [25].

\subsection{Antioxidant activity}

The measurement of MDA and SOD are useful in minimizing the damaging effects caused by ROS [2931]. Currently, LPS treated mice showed an increased level of MDA in the lung (Fig. 10a). In contrast, the SOD was greatly decreased (Fig. 10b). Treatment with BG@BSA NPs reduced MDA and increased SOD in the lung. Similar results have been documented using BM 60 [25].

\subsection{MPO and inflammatory cytokine activity}

MPO is important for acute and chronic inflammations [32]. MPO measurement indicates neutrophil confiscation in tissue. In this study, the increased level of MPO was observed in lung tissues of LPS challenged animals. However, BG@BSA NPs have the ability to attenuate the neutrophil infiltration in the lungs indicating their protective effects against inflammation (Fig. 11a). The inflammatory cytokines in BALF serve as a marker to evaluate the inflammatory responses [33,34]. BG@BSA NPS may inhibit the expression of TNF-a, IL-1b, and IL-6. The TNF-a, IL-1b, and IL-6 in treated groups. Overall, the treatment of BG@BSA NPS decreased pro-cytokines while compared to control (Fig. 11b-d). Similarly, the inflammatory cells and TNF-a, IL-1b, and IL-6 production were greatly inhibited by BM60 [25].

\subsection{Histopathology analysis}

Neutrophils, one of the most important components of the initial innate immune response in the lung against bacterial infections are the earliest immune cells to be recruited to the site of injury and express multiple cytotoxic products [25]. In this study, histopathological examination was performed to reveal the protective effect of BG@BSA NPs on acute lung infection (Fig. 12). In LPS induced acute lung injury (ALI), the neutrophils accumulated in the lungs, changed the expressions of pro-inflammatory cytokines, such as TNF-a, IL-1b, and IL- 6 and finally led to the pulmonary injury. In this study, we found that the 
neutrophils clearly increased in lung tissues after LPS exposure and the effect of BG@BSA NPs on the number of inflammatory cells in BALF was observed. The number of total cells and neutrophils increased significantly after LPS treatment. BG@BSA NPs dose dependently inhibited the number of total cells and neutrophils in BALF induced by LPS. As expected, BG@BSA NPs pre-treatment significantly decreased the neutrophils in lung tissues. It was evident that the histopathological damage and neutrophil infiltration was greatly inhibited by BG@BSA NPs. This indicates that BG@BSA NPs may be used to treat lung infections.

\section{Conclusion}

A biodegradable bergenin loaded BSA NPs was designed to be used as a drug delivery vehicle. Proteindrug nano particulates was produced following the desolvation technique. This approach eliminates the use of toxic organic compounds. The formed BG@BSA NPs were analyzed by AFM, FE-SEM and XPS. In this study, the combination of bergenin did not alter the size of NPs and it proves the ability for the application of drug delivery. BSA NPs showed enhanced constant release of bergenin. The result highlights the fact that human serum albumin may be used as an alternative instead of BSA. Our results show that the BG@BSA NPs had strong antioxidative and anti-inflammatory activities against LPSinduced lung oxidative stress and inflammation both in NR8383 macrophage cells and mouse models. The results from histopathological analyses confirmed those enzymatic assay data. This study concludes the therapeutic potential of bergenin loaded BSA NPs for the treatment of acute lung injury in future clinical applications.

\section{Declarations}

\section{Ethics approval and consent to participate}

In this study, all animal procedures were performed in accordance with the Guidelines for Care and Use of Laboratory Animals of "First People's Hospital of Wenling" and all experiments were conducted with the approval of the Animal Ethical Committee at the First People's Hospital of Wenling, PR China.

\section{Consent for publication}

Not applicable

\section{Availability of data and materials}

Not applicable

\section{Competing Interests}

The authors declare that they have no competing interests.

\section{Funding}


Not applicable

\section{Authors' contributions}

Lingqiao Yan contributed to the conception and coordination of the study, the assessment of the quality of trials, and drafting the manuscript. Hui Chen contributed to the extracting and screening of all references for eligibility, the assessment of the quality of trials, and drafting the manuscript. Mindan Xie contributed to the conception and coordination of the study, the assessment of the quality of trials, and drafting the manuscript.

\section{Acknowledgements}

Not applicable

\section{References}

1. Rubenfeld, G. D., and M. S. Herridge. 2007. Epidemiology and outcomes of acute lung injury. Chest 131: 554-559.

2. Matthay, M. A. 2008. Treatment of acute lung injury: clinical and experimental studies. Proc Am Thorac Soc. 5: 297-301.

3. Girard, T. D., and G. B. Bernard. 2007. Mechanical ventilation in ARDS: a state-of-the-art review. Chest 131: 921-933.

4. Sadikot, R. T., J. W. Christman, and T. S. Blackwell. 2004. Molecular targets for modulating lung inflammation and injury. Curr Drug Targets 5: 581-588.

5. Yuan, Z., M. Syed, D. Panchal, M. Joo, C. Bedi, S. Lim, H. Onyuksel, I. Rubinstein, M. Colonna, and R. T. Sadikot. 2016. TREM-1-accentuated lung injury via miR-155 is inhibited by LP17 nanomedicine. Am J Physiol Lung Cell Mol Physiol. 310: L426-L438.

6. Sadikot, R. T., and I. Rubinstein. 2009. Long-acting, multi-targeted nanomedicine: addressing unmet medical need in acute lung injury. J Biomed Nanotechnol. 5: 614-619.

7. Foldvari, M., and N. Elsabahy. 2011. Nanotechnology enables superior medical therapies. Curr Drug Deliv 8: 225-226.

8. Dames, P., B. Gleich, A. Flemmer, K. Hajek, N. Seidl, F. Wiekhorst, D. Eberbeck, D, I. Bittmann, C. Bergemann, T. Weyh, L. Trahms, and J. Rosenecker. 2007. Targeted delivery of magnetic aerosol droplets to the lung. Nat Nanotechnol. 2: 495-499.

9. Kim, B. Y., J. T. Rutka, and W. C. Chan. 2010. Nanomedicine. N Engl J Med 363: 2434-2443.

10. Singh, S. 2010. Nanomedicine-nanoscale drugs and delivery systems. J Nanosci Nanotechnol. 10: 7906-7918.

11. Buxton, D. B. 2009. Nanomedicine for the management of lung and blood diseases. Nanomedicine. 4: 331-339. 
12. Roy, I., and N. Vij. 2010. Nanodelivery in airway diseases: challenges and therapeutic applications. Nanomedicine. 6: 237-244.

13. Klingler, C., B. W. Müller, and H. Steckel. 2009. Insulin-micro- and nanoparticles for pulmonary delivery. Int J Pharm. 377: 377: 173-179.

14. Shuvaev, V. V., and V. R. Muzykantov. 2011. Targeted modulation of reactive oxygen species in the vascular endothelium. J Control Release. 153: 56-63.

15. Sung, J. C., B. L. Pulliam, and D. A. Edwards. 2007. Nanoparticles for drug delivery to the lungs. Trends Biotechnol 25: 563-570.

16. Schleh, C., B. Rothen-Rutishauser, and W. G. Kreyling. 2011. The influence of pulmonary surfactant on nanoparticulate drug delivery systems. Eur J Pharm Biopharm. 770: 350-352.

17. Weber, C., J. Kreuter, and K. Langer. 2000. Desolvation process and surface characteristics of HASnanoparticles. Int J Pharm. 196: 197-200.

18. Bhushan, B., P. Dubey, S. Uday Kumar, A. Sachdev, I. Mataia, and P. Gopinath. 2015.

Bionanotherapeutics: niclosamide encapsulated albumin nanoparticles as a novel drug delivery system for cancer therapy. RSC advances 5: 12078.

19. Hossain, M., A. Y. Khan, and G. S. Kumar. 2011. Interaction of the anticancer plant alkaloid sanguinarine with bovine serum albumin. PLoS One. 6: e18333.

20. Maltas, E. 2014. Binding interactions of niclosamide with serum proteins. J. Food Drug Anal. 22: 549-555.

21. Abdelwahed, W., G. Degobert, S. Stainmesse, and H. Fessi. 2006. Freeze-drying of nanoparticles: formulation, process and storage considerations. Adv. Drug Delivery Rev. 58: 1688-1713.

22. Peer, D., J. M. Karp, S. Hong, O. C. Farokhzad, R. Margalit, and R. Langer. 2007. Nanocarriers as an emerging platform for cancer therapy. Nature Nanotechnology 2: 751-760.

23. Guo, H., S. Fei, Y. Zhang, Y.u. Zhang, J. Gou, L. Zhang, H. He, T. Yin, Y. Wang, and X. Tang. 2016. Teniposide-loaded multilayer modified albumin nanoparticles with increased passive delivery to the lung. RSC advances 6: 81110.

24. Sripriyalakshmi, S., C. H. Anjali, C. G. P. Doss, B. Rajith, and A. Ravindran. 2014. BSA nanoparticle loaded atorvastatin calcium-a new facet for an old drug. PLoS One. 9: e86317.

25. Wang, Y., W. Huang, J. Zhang, M. Yang, Q. Qi, K. Wang, A. Lia, and Z. Zhao. 2016. The therapeutic effect of Bletilla striata extracts on LPS-induced acute lung injury by regulation of inflammation and oxidation. RSC advances 6: 89338.

26. Nanashima, N., M. Akita, T. Yamada, T. Shimizu, H. Nakano, Y. Fan, and S. Tsuchida. 2008. The hairless phenotype of the Hirosaki hairless rat is due to the deletion of an $80-\mathrm{kb}$ genomic DNA containing five basic keratin genes. Journal of Biological Chemistry 283: 16868-16875.

27. Ma, C., J. Liu, R. Qu, and S. Ma. 2014. Chin, Tectorigenin inhibits the inflammation of LPS-induced acute lung injury in mice. Journal of Natural Medicines 12: 841-846. 
28. Huang, X., Y. Liu, Y. Lu, and C. Ma. 2015. Anti-inflammatory effects of eugenol on lipopolysaccharideinduced inflammatory reaction in acute lung injury via regulating inflammation and redox status. International Immunopharmacology 26: 265-271.

29. T"ur"ut, H., H. Ciralik, M. Kilinc, D. Ozbag, and S. S. Imrek. 2009. Effects of early administration of dexamethasone, $\mathrm{N}$-acetylcysteine and aprotinin on inflammatory and oxidant-antioxidant status after lung contusion in rats. Injury. 40: 521-527.

30. Ohkawa, H., N. Ohishi, and K. Yagi. 1979. Assay for lipid peroxides in animal tissues by thiobarbituric acid reaction. Analytical Biochemistry 95: 351-358.

31. Koul, A., V. Bhatia, and M. P. Bansal. 2001. Effect of alpha-tocopherol on pulmonary antioxidant defence system and lipid peroxidation in cigarette smoke inhaling mice. BMC Biochem 2: 14712091.

32. Jiang, W., F. Luo, Q. Lu, J. Liu, P. Li, X. Wang, Y. Fu, K. Hao, T. Yan, and X. Ding. 2016. ChemicoBiological Interactions 243: 127-134.

33. Ma, J., H. Xu, J. Wu, C. Qu, F. Sun, and S. Xu. 2015. Linalool inhibits cigarette smoke-induced lung inflammation by inhibiting NF-KB activation. International Immunopharmacology 29: 708-713.

\section{Figures}


Fig. 1

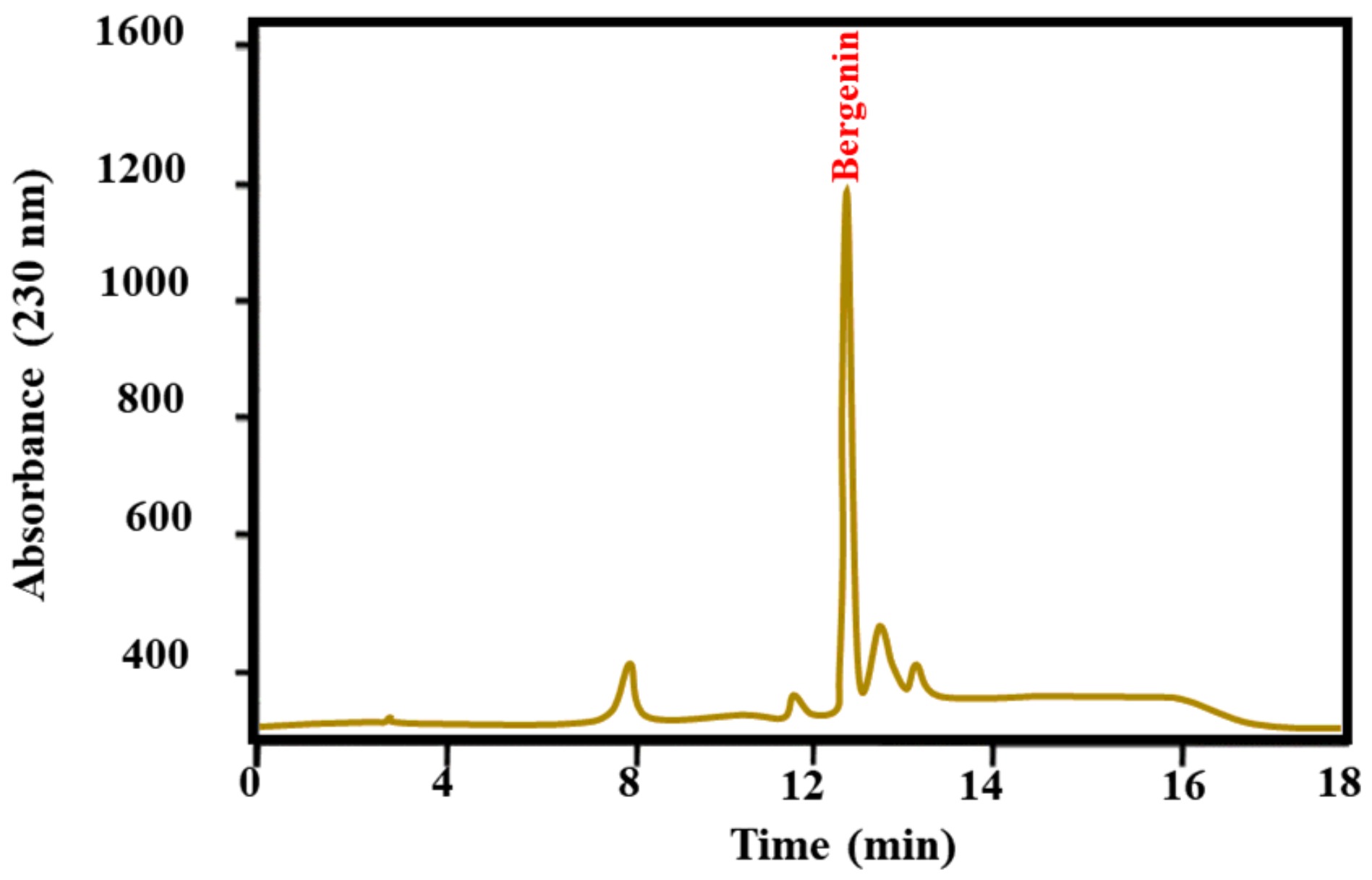

Figure 1

HPLC chromatogram of bergenin standard solution $(50 \mu \mathrm{g} / \mathrm{mL})$. 
Fig. 2

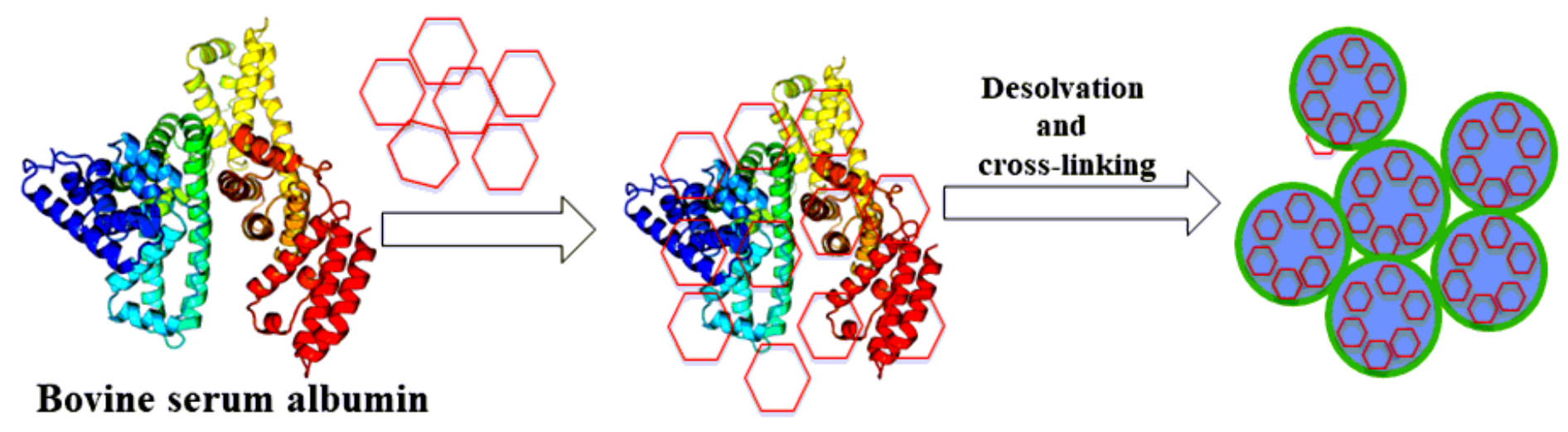<smiles>COc1c(O)cc2c(c1O)C1OC(CO)[C@@H](O)C(O)[C@H]1OC2=O</smiles>

Bergenin

Figure 2

Schematic diagrams of the bergenin loaded albumin nanoparticles (BG@BSANPs) formation. 
Fig. 3
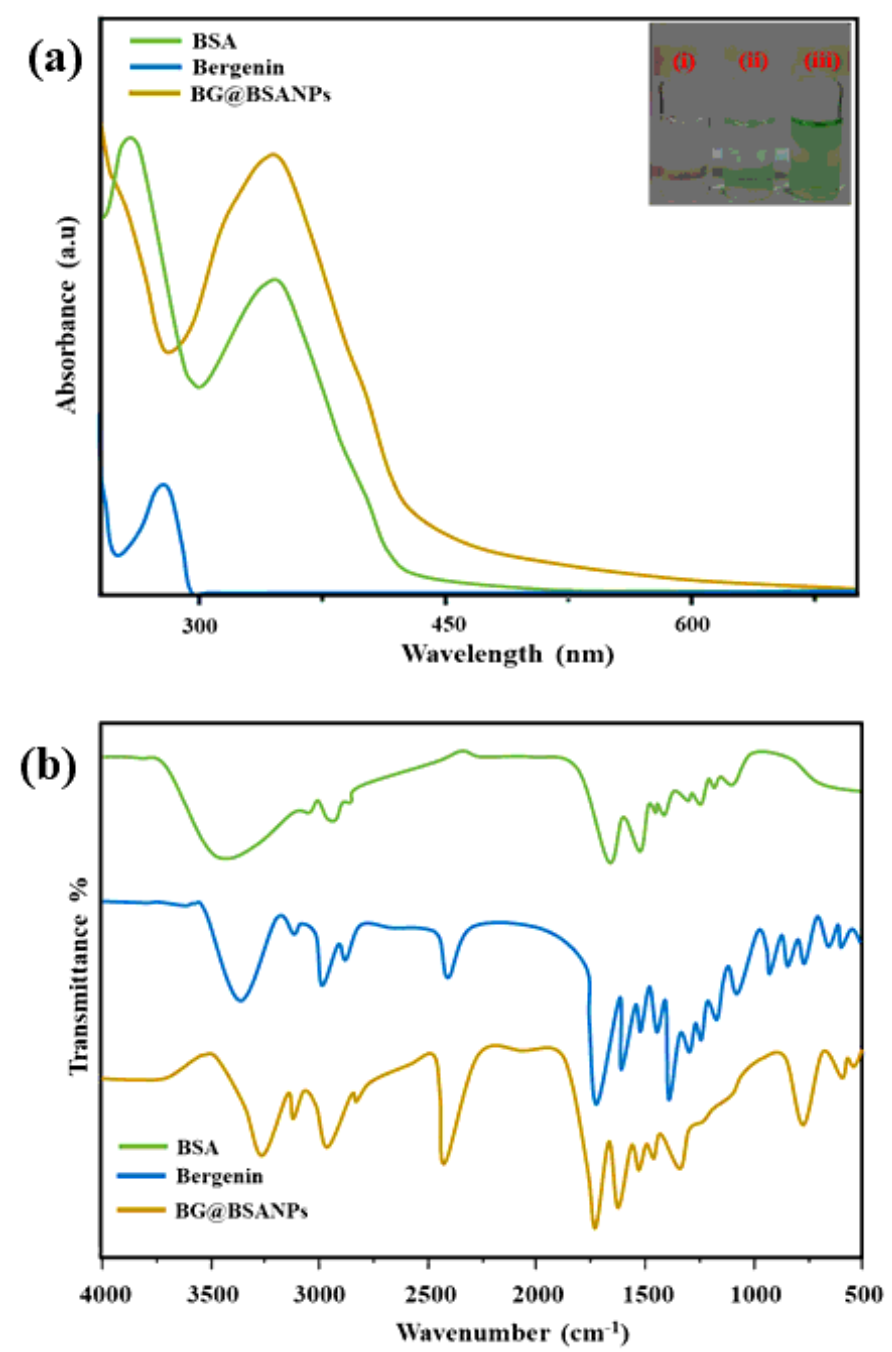

Figure 3

(a) UV-visible spectroscopy and (b) FT-IR analysis of bergenin loaded albumin nanoparticles. Insert figure shows a colour variation of (i) bovine serum albumin, (ii) bergenin and (iii) bergenin loaded albumin nanoparticles (BG@BSANPs). 
Fig. 4
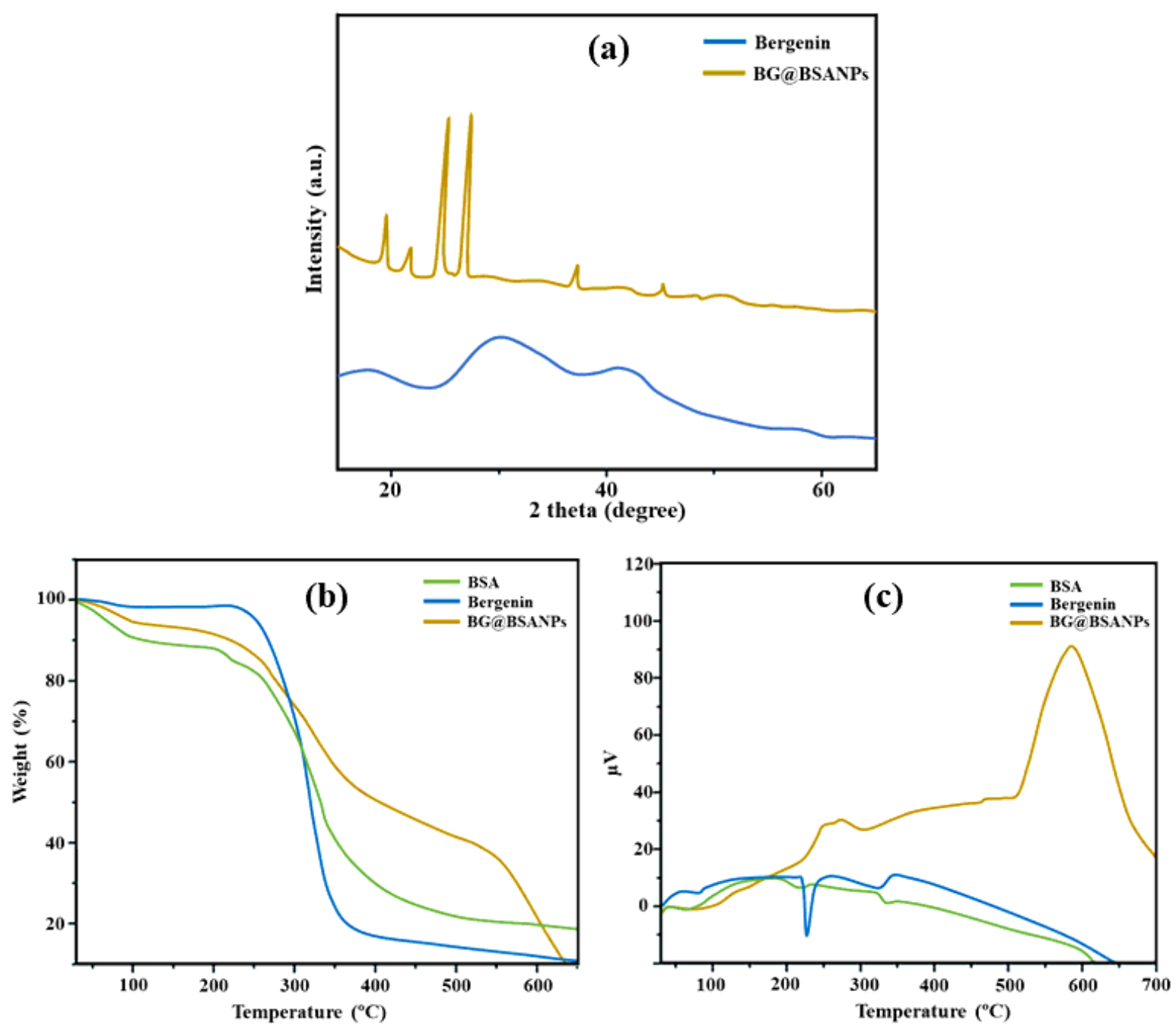

Figure 4

(a) XRD (b) TGA and (c) DTA analysis of BG@BSANPs. 
Fig. 5

$\mathbf{A}$

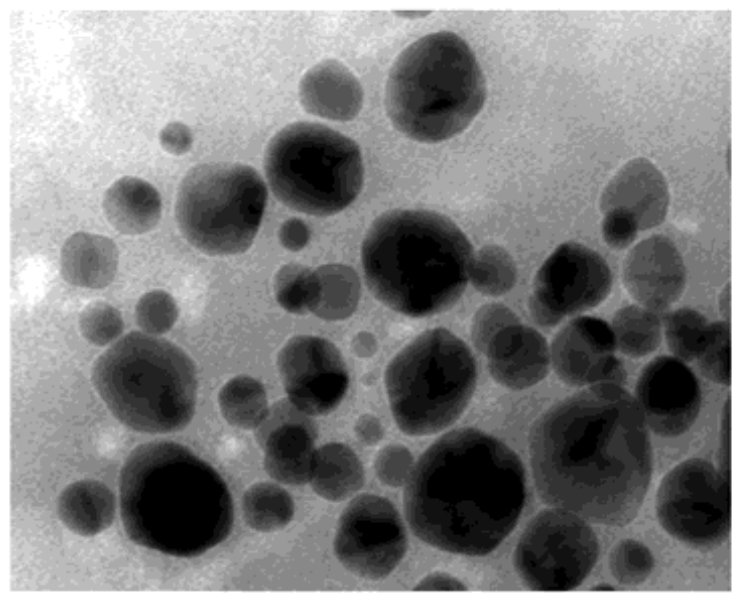

C

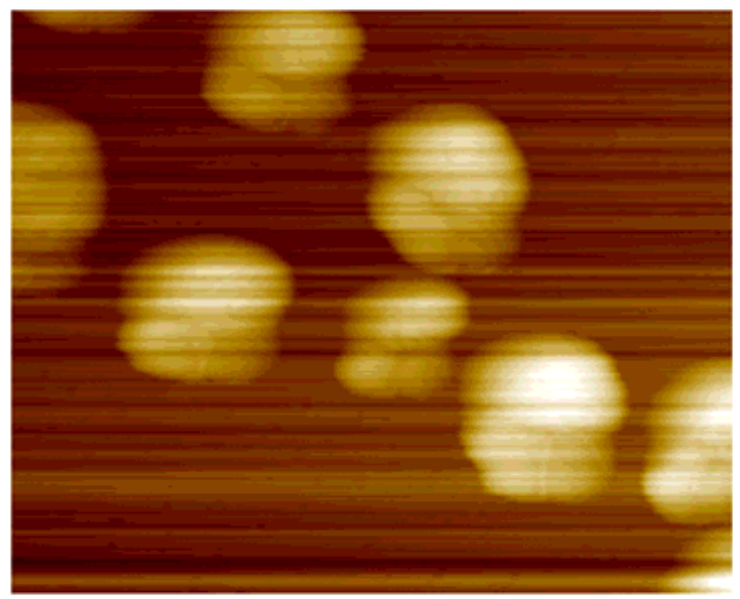

B

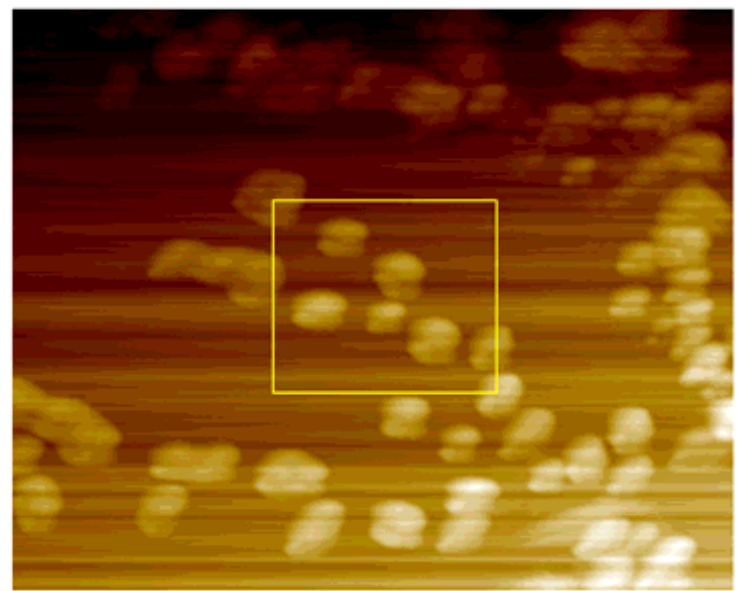

D

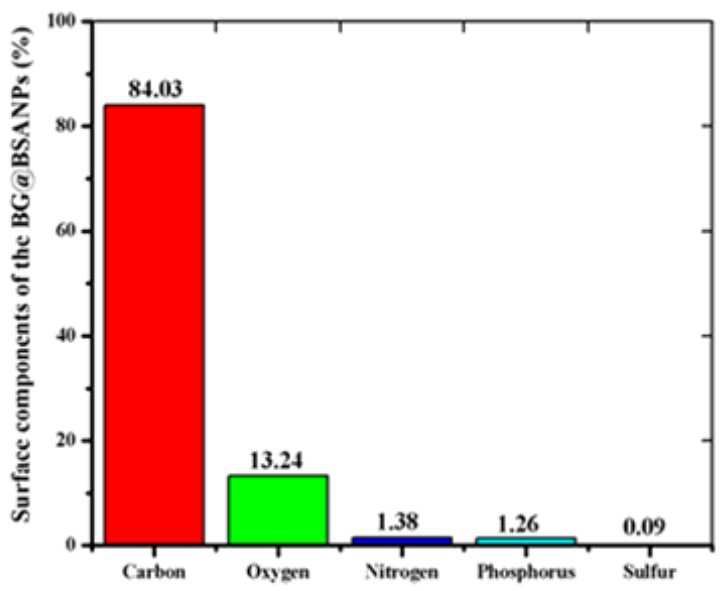

\section{Figure 5}

Morphological analysis of BG@BSANPs; (A) TEM (B-C) AFM and (D) XPS analysis. 
Fig. 6
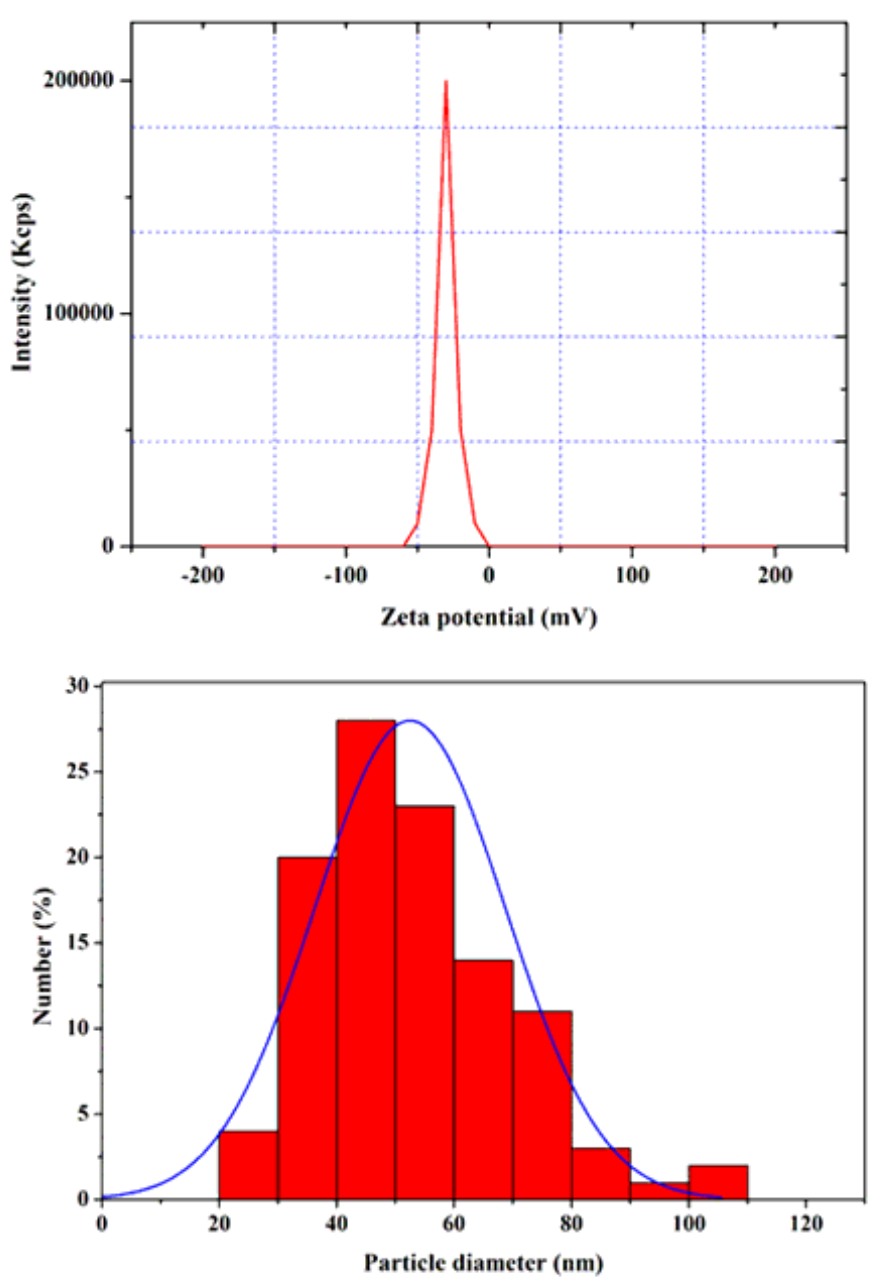

Figure 6

Zeta potential and particle analysis of BG@BSANPs. 
Fig. 7

(a)

\begin{tabular}{cccc}
\hline $\begin{array}{c}\text { S.N } \\
\mathbf{0}\end{array}$ & $\begin{array}{c}\text { BSA } \\
\text { concentration } \\
(\mathbf{m g})\end{array}$ & $\begin{array}{c}\text { Bergenin } \\
\text { concentration } \\
(\mathbf{m g})\end{array}$ & $\begin{array}{c}\text { Entrapment } \\
\text { efficiency } \\
(\%)\end{array}$ \\
\hline 1 & 25 & 5 & $73.65 \pm 2.105$ \\
2 & 25 & 10 & $86.52 \pm 1.672$ \\
3 & 25 & 15 & $93.47 \pm 1.347$ \\
4 & 25 & 20 & $82.12 \pm 2.107$ \\
5 & 25 & 25 & $74.85 \pm 2.132$ \\
\hline
\end{tabular}

(b)

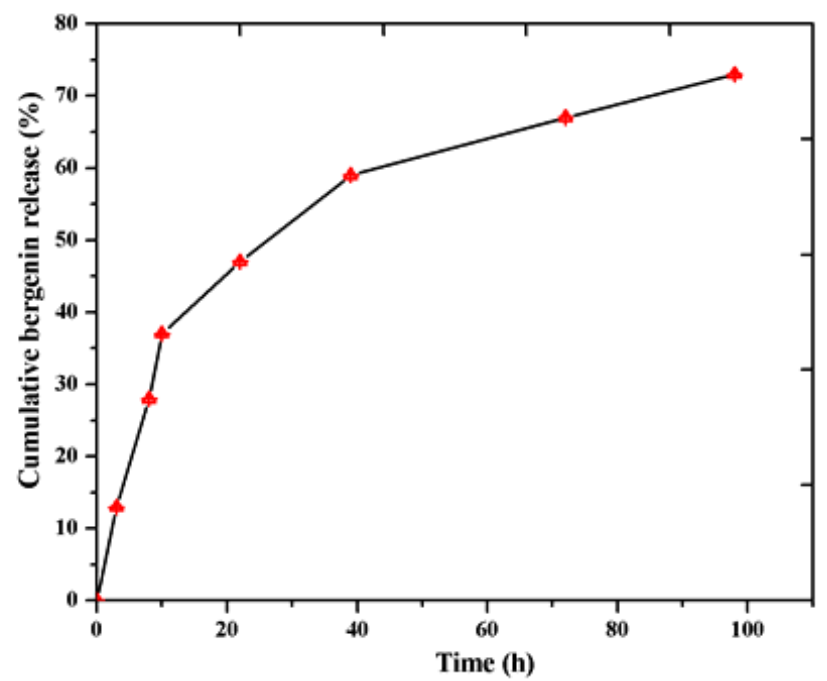

Figure 7

The entrapment efficiency of BG@BSANPs with varying bergenin concentrations (b) bergenin release profile from BG@BSANPs in PBS. 


\section{Fig. 8}
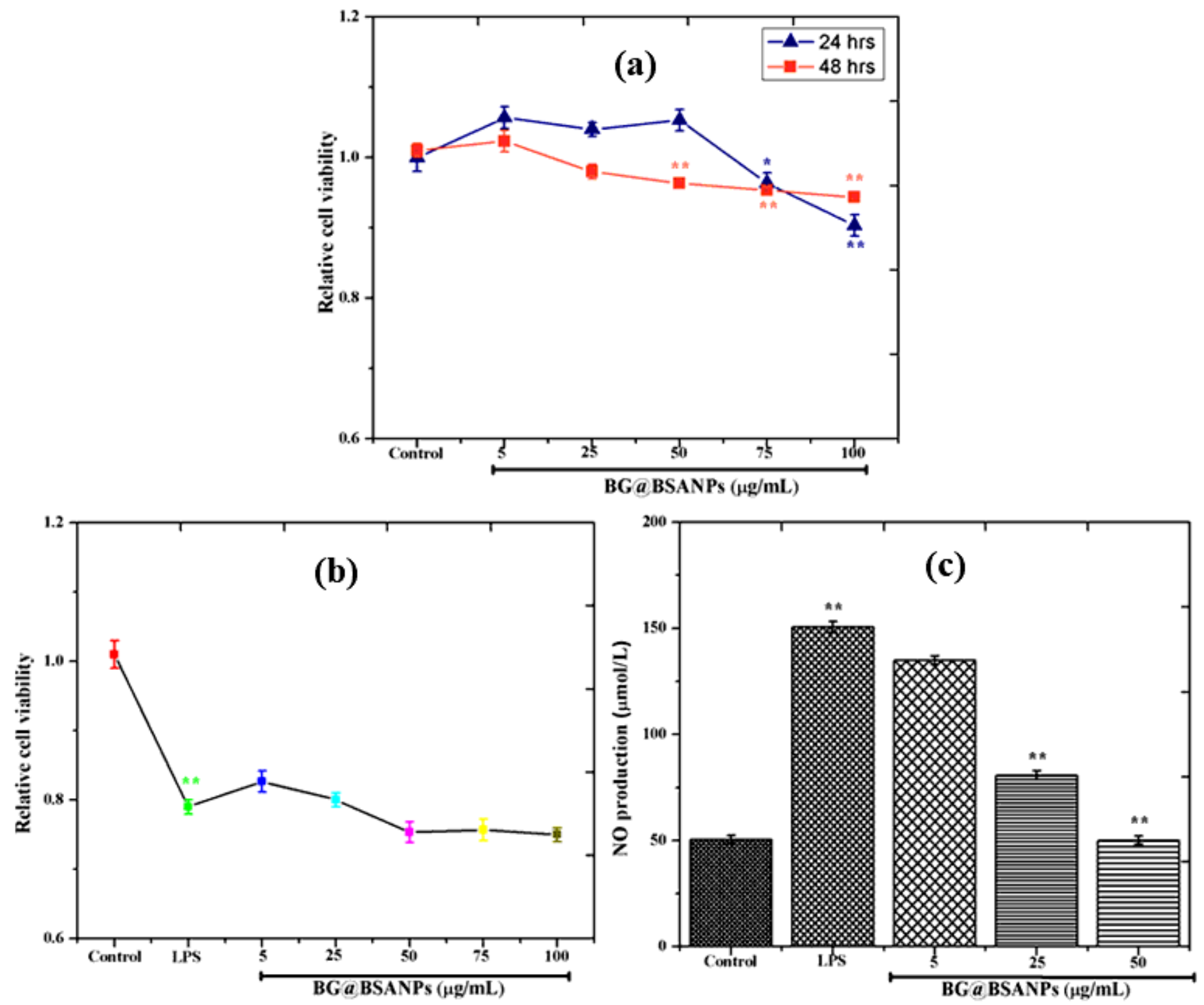

Figure 8

The effects of BG@BSANPs on the cell viability of NR8383 cells at 24 and $48 \mathrm{~h}$, as revealed by the CCK8 assays. (b) The NR8383 cells were pretreated with BG@BSANPs for $2 \mathrm{~h}$ before $1 \mu \mathrm{g} \mathrm{mL}-1 \mathrm{LPS}$ challenge (C) Effect of BG@BSANPs on LPS-induced NO production in NR8383 cells. A p-value *p $<0.05,{ }^{*} p<0.01$ vs. LPS. The asterisk * and ** indicate the significant differences $p<0.05$ and $p<0.01$ between the control and experimental groups, respectively., 
Fig. 9

(a)

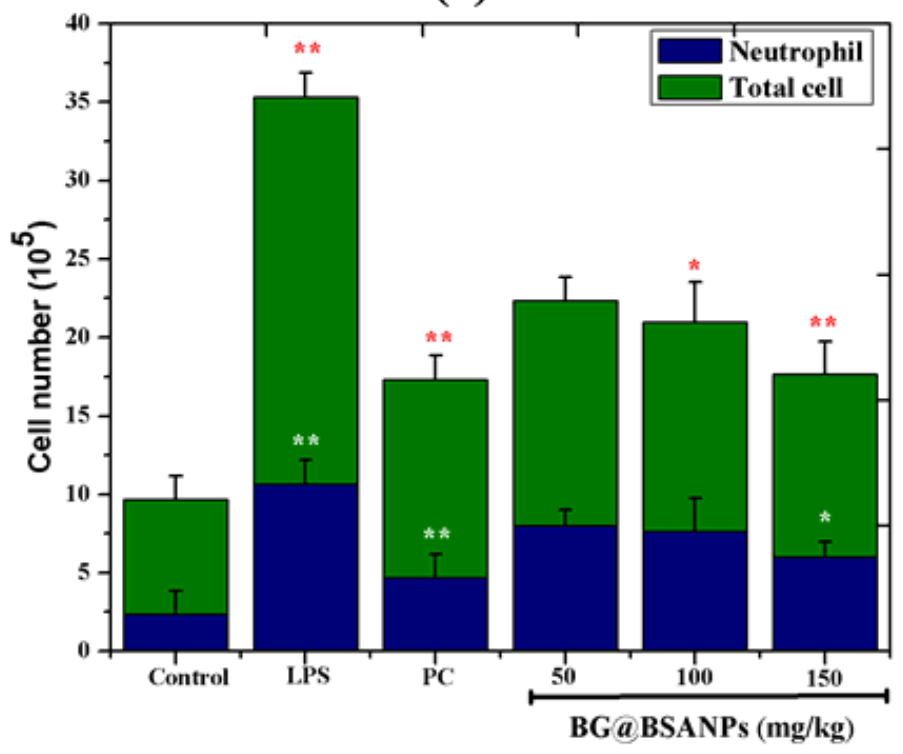

(b)

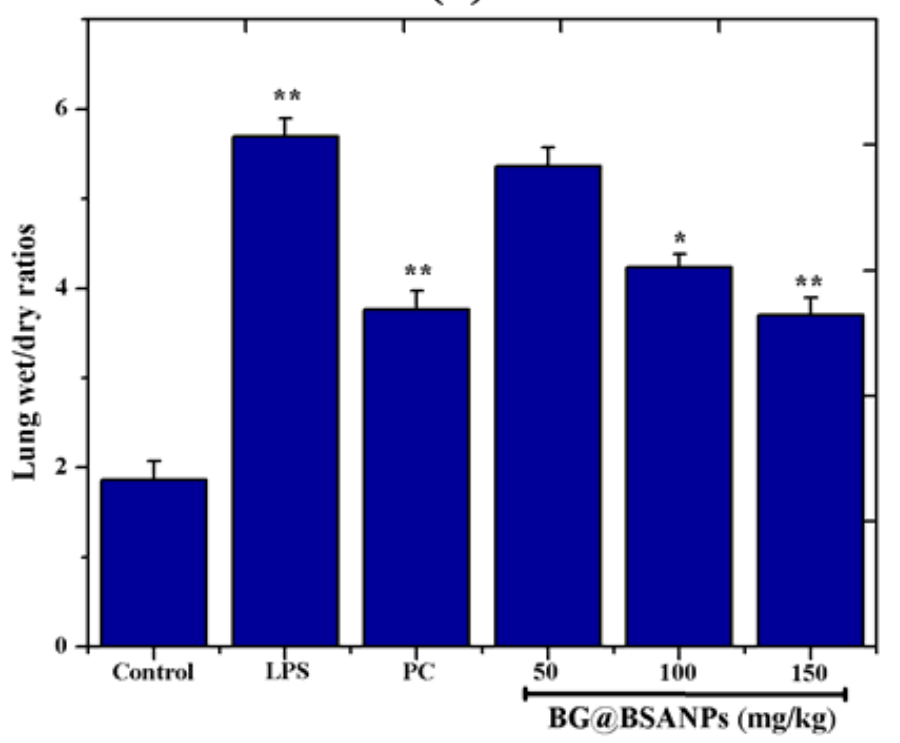

Figure 9

(A) Total cell and neutrophil accounts in BALF. (B) Effects of BG@BSANPs on LPS-induced lung wet-todry ratios. PC: positive control group, mice treated with Dex. The asterisk * and ** indicate the significant differences $p<0.05$ and $p<0.01$ between the control and experimental groups respectively. 
Fig. 10

(a)

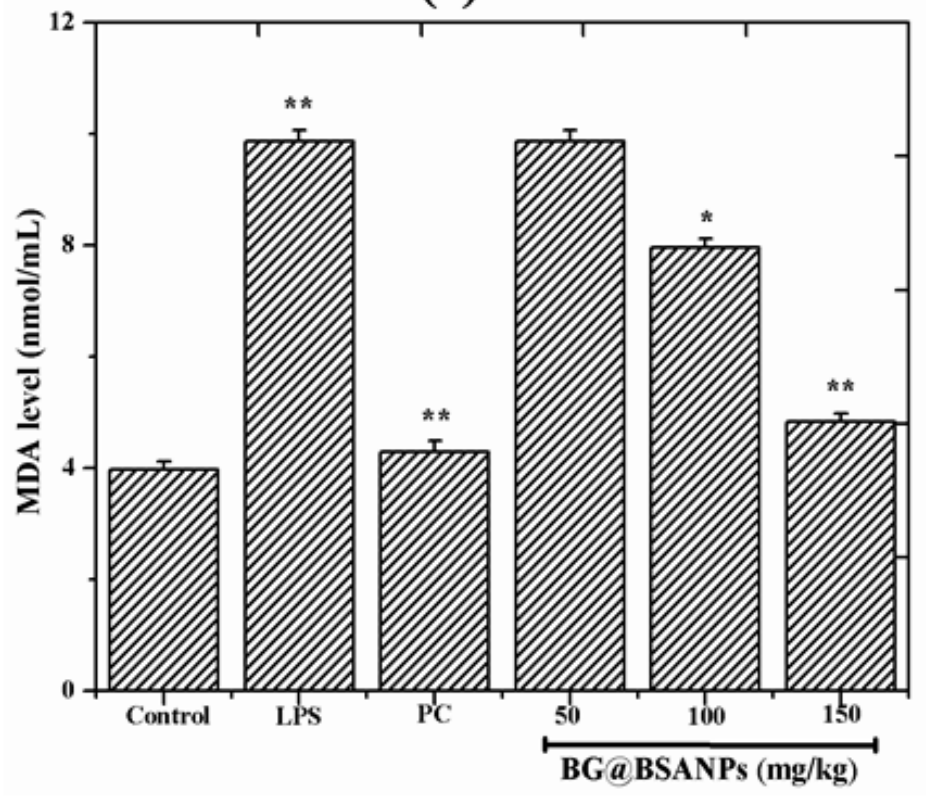

(b)

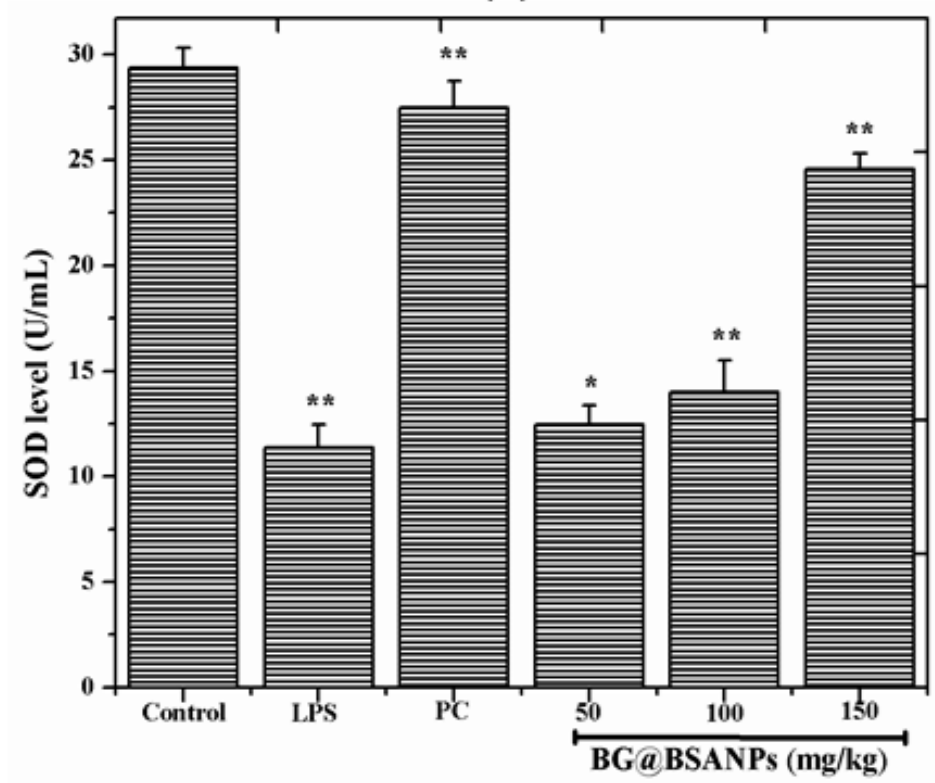

Figure 10

Effects of BG@BSANPs on the levels of MDA and SOD in the lungs. 
Fig. 11
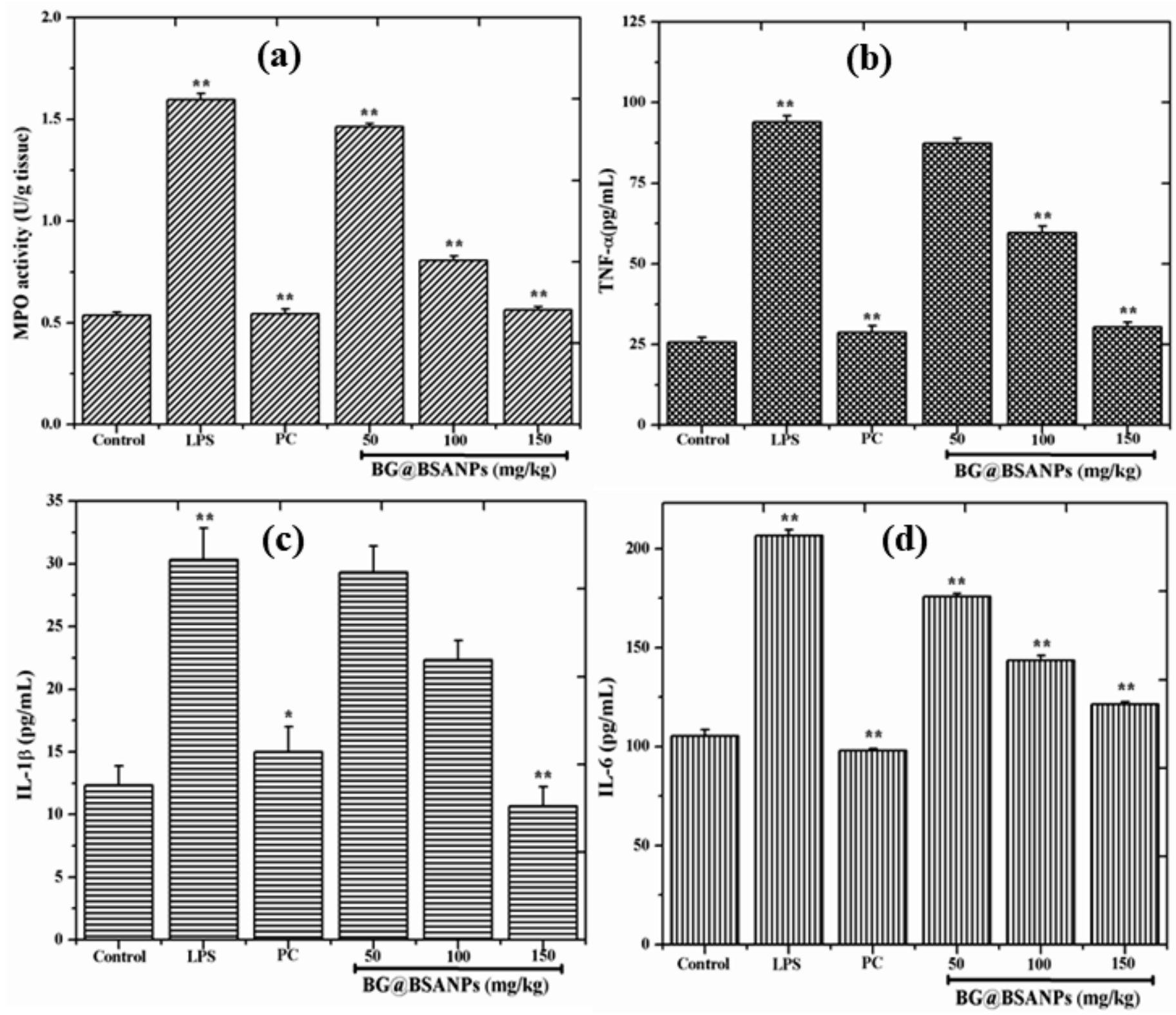

Figure 11

Effects of BG@BSANPs on MPO activity in lung homogenate, and cytokines in BALF. 
Fig. 12
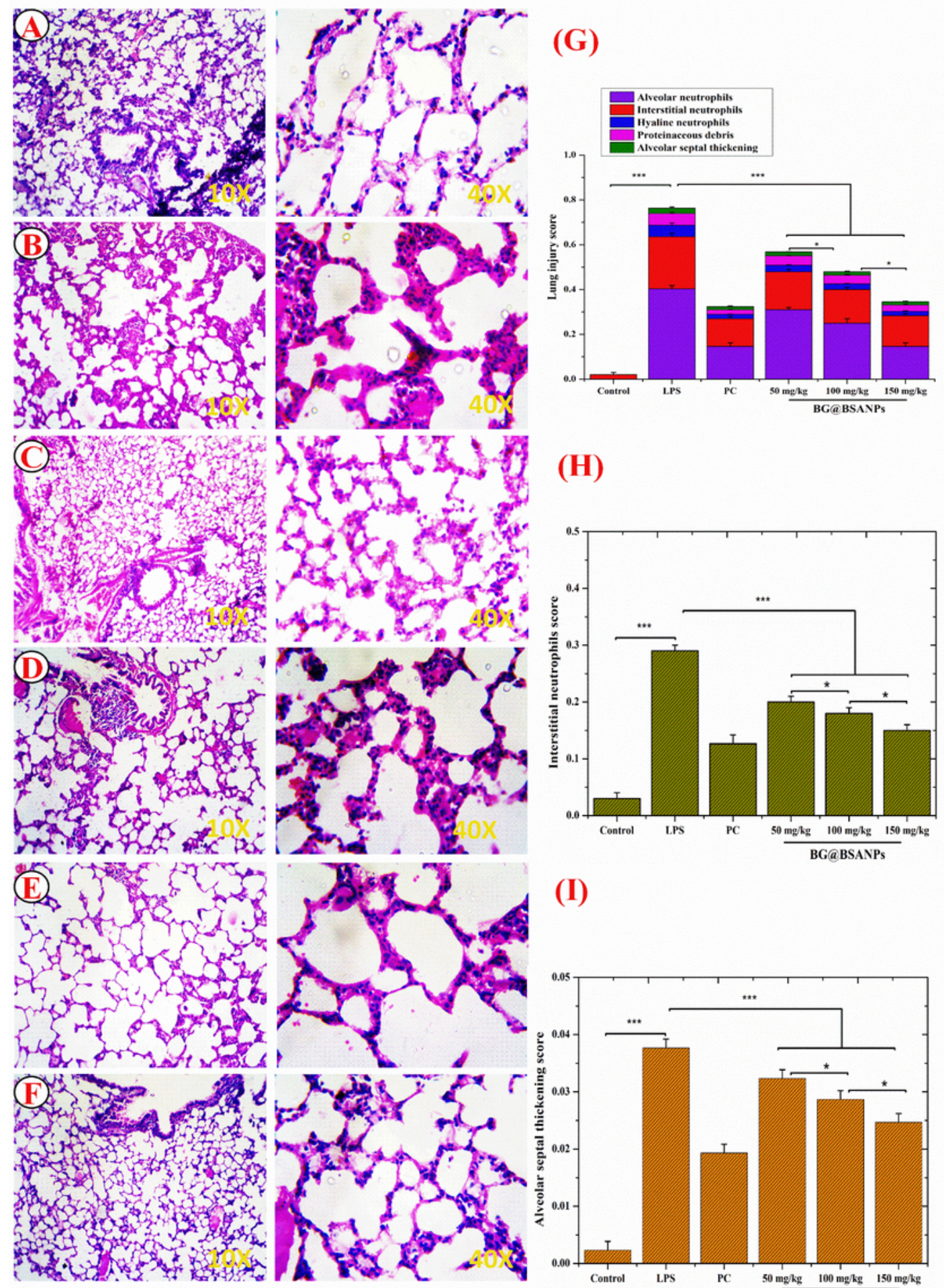

(H)

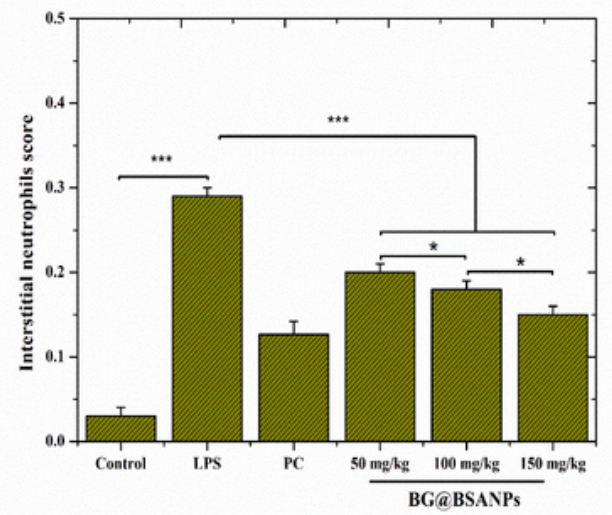

(I)

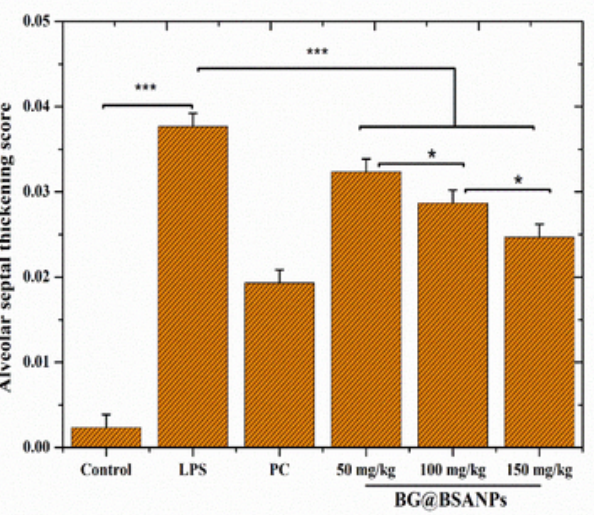

Figure 12

Histopathological variation of lung tissues with different treatments. (A) Control, (B) LPS challenged (C) Positive control and (D-F) the animals treated with various concentrations of BG@BSANPs such as 50 and 100 and $150 \mathrm{mg} / \mathrm{kg}$ respectively. The asterisk * and *** indicate the significant differences $p<0.05$ and $p<0.01$ between the control and experimental groups respectively. 


\section{Supplementary Files}

This is a list of supplementary files associated with this preprint. Click to download.

- GraphicalAbstract.tif 